\title{
Capsule Commentary on Egede et al., Telephone-Delivered Behavioral Skills Intervention for African American Adults with Type 2 Diabetes: A Randomized Controlled Trial
}

\author{
Augustine Chavez, MD \\ Mayo Clinic, Scottsdale, AZ, USA. \\ J Gen Intern Med 32(7):798 \\ DOI: $10.1007 / \mathrm{s} 11606-017-4042-\mathrm{x}$ \\ (c) Society of General Internal Medicine 2017
}

$\mathrm{T}$ he article by Egede et al. examines the efficacy of behavioral-based interventions in reducing $\mathrm{A} 1 \mathrm{C}$ levels in African Americans with uncontrolled diabetes. ${ }^{1}$ The aim of this study is important as culturally competent interventions, delivered by non-physician providers, that address health disparities in high-risk populations are paramount to the Triple Aim and invaluable in value-based care models. The study findings indicate there was no statistically significant benefit in the intervention arms compared to controls. Considering why an effect was not detected highlights the challenges inherent to research involving behavioral interventions in which both the efficacy of the intervention and the proficiency of the person delivering the intervention affect patient outcomes.

While one explanation is that the interventions actually were no better than the control, another plausible explanation is that the study's inability to demonstrate benefit reflects a consistent research finding that outcomes vary dramatically depending on the provider to whom the patient is assigned. Miller et al. demonstrated that provider skill, such as accurate expressions of empathy, was a more robust predictor of outcome than the content of the intervention. ${ }^{2}$ Even when trained to deliver standardized treatment, as providers in this study were, providers often differ significantly in their effectiveness. For example, Mullin et al. showed that after 6 months of training in motivational interviewing, no provider was able to demonstrate even beginning proficiency. ${ }^{3}$ Similarly, other research shows that even providers with demonstrated proficiency are markedly inconsistent in their treatment fidelity. ${ }^{4}$

For this reason, the use of validated fidelity tools in research is vital to differentiate treatment effects from therapist effects. These tools already exist, such as MITI 4.2.1 for Motivational Interviewing, and their consistent application can help guide future investigations toward a more nuanced understanding of mechanisms of change in behavioral interventions. Similarly, fidelity monitoring in clinical practice can assure effective translation of research findings to patient care. Taking these steps will improve both research processes and patient outcomes.

Corresponding Author: Augustine Chavez, MD; Mayo Clinic, Scottsdale, AZ, USA (e-mail: Chavez.Augustine@mayo.edu).

Compliance with Ethical Standards:

Conflict of Interest: The author has no conflicts with this article.

\section{REFERENCES}

1. Egede LE, Williams JS, Voronca DC, Gebregziabher M, Lynch CP. Telephone-delivered behavioral skills intervention for African American adults with type 2 diabetes: a randomized controlled Trial. J Gen Intern Med. doi: 10.1007/s11606-017-4023-0.

2. Miller WR, Taylor CA, West JC. Focused versus broad-spectrum behavior theraoy for problem drinkers. J Consult Clin Psychol. 1980;48(5):590-601.

3. Mullin DJ, Firsberg L, Savageau JA, Saver B. Challenges in developing primary care physicians' motivational interviewing skills. Fam Syst Health. 2015;33(4):330-8.

4. Imel ZE, Baldwin SA, Baer JS, Hartzler B, Dunn C, Rosengren DB, Atkins DC. Evaluating therapist adherence in motivational interviewing by comparing performance with standardized and real patients. J Consult Clin Psychol. 2014;82(3):472-81. 